\title{
DESAIN DAN IMPLEMENTASI KONTROL KESEIMBANGAN KENDARAAN RODA DUA DENGAN KONTROL LOGIKA SAMAR MENGGUNAKAN MIKROKONTROLER
}

\author{
Bonaventura Dhimas Gutama \\ Fakultas Teknik Elektro, Universitas Telkom \\ bonaventuradhimas@gmail.com
}

\begin{abstract}
Abstrak
Pada penelitian ini dilakukan pengontrolan keseimbangan kendaraan roda dua dengan memanfaatkan momentum sudut pada gyroscope. Penentukan kemiringan gyroscope dilakukan dengan teknik pengontrolan logika samar untuk mengatur gerak servo. Sensor yang digunakan adalah accelerometer yang sinyal keluarannya telah diperbaiki oleh estimator filter Kalman. Semua proses dijalankan dengan menggunakan mikrokontroler STM32F4. Masukan pengontrol logika samar adalah nilai error dan delta error. Nilai error merupakan selisih pembacaan sensor dengan nilai set point, sedangkan delta error adalah selisih error saat ini dengan error sebelumnya. Pengambilan keputusan dilakukan dengan metode Mamdani Inference System dan Weight Average Defuzzification. Prototipe yang telah dibuat telah berhasil mempertahankan posisi tegaknya dengan kemiringan hingga $\pm 5^{\circ}$.
\end{abstract}

Kata Kunci: kontrol keseimbangan, logika samar, STM32F4, filter Kalman, gyroscope

Abstract

In this research, the balance of the two-wheeled vehicle is controlled by utilizing the angular momentum of the gyroscope. Determines the slope of the gyroscope is done with logic control techniques vague to govern the motion of the servo. The sensor used is the accelerometer output signal has been improved by Kalman Filter estimator. All the process is executed by using a microcontroller STM32F4. Logic controller Input is an error and delta error value. Error value is the difference between the sensor readings with set point value, while the delta error is the difference between the current error with the previous error. Decisionmaking is done by the method of Mamdani Inference System and Weight Average Defuzzyfication. The prototype that has been made has managed to keep upright position with tilt up to $\pm 5^{\circ}$.

Keywords: balancing control, fuzzy logic, STM32F4, Kalman filter, gyroscope

\section{Pendahuluan}

Kendaraan roda dua merupakan alat transportasi yang memiliki efisiensi bahan bakar tinggi akan tetapi memiliki resiko kecelakaan yang tinggi. Resiko yang tinggi tersebut diakibatkan oleh faktor keseimbangan yang dikendalikan sepenuhnya oleh pengendara. Berbeda dengan mobil yang tetap stabil tanpa perlu pengendaranya menjaga kestabilan, mobil memiliki kenyamanan yang lebih baik dari sepeda motor.

Banyaknya mobil di jalan raya yang berisikan hanya satu hingga dua orang mengakibatkan kemacetan. Dalam kondisi demikian terjadi pemborosan bahan bakar, padahal persediaan bahan bakar fosil di dunia diperkirakan akan segera habis dalam beberapa tahun kedepan. Oleh sebab itu diperlukan sarana transportasi yang menggunakan energi terbarukan serta memiliki penggabungan keuntungan mobil dan sepeda motor.

Pada penelitian ini, telah dirancang sebuah inovasi protoripe kendaraan roda dua dengan kenyamanan mobil. Prototipe yang dirancang menggunakan sensor accelerometer, aktuator berupa dua buah gyroscope, dan untuk pengontrol digunakan mikrokontroler STM32F4.
Pengontrolan yang digunakan dalam penelitian ini adalah kontrol logika samar dengan dua buah masukan berupa nilai error posisi yang dibandingkan dengan set poin dan nilai selisih error saat ini dengan error sebelumnya. Pembacaan error posisi dilakukan oleh sensor accelerometer yang diperbaiki dengan filter kalman untuk memperbaiki pembacaan sensor terhadap noise.

\section{Gyroscope}

Gyroscope adalah sebuah cakram yang memiliki massa dan berputar pada porosnya. Ketika cakaram yang memiliki momen inersia $I$ (dalam satuan kgm) dan berputar dengan kecepatan $\omega$ (dalam satuan $\mathrm{rad} / \mathrm{s}$ ) maka akan timbul suatu momentum sudut $L$ (dalam satuan $\mathrm{kgm} \mathrm{rad} / \mathrm{s}$ ) yang arahnya tegak lurus dengan arah putaran cakram tersebut yang dapat dilihat pada persamaan 1 .

$$
L=I \omega \frac{2 \pi}{60}
$$

Gyroscope akan selalu mempertahankan posisinya ketika frame-nya berubah-ubah karena 
adanya momentum sudut saat cakramnya berputar. Dengan konsep ini jika dilakukan secara kebalikan dalam artian posisi gyroscope diubah-ubah agar arah momentum sudutnya berubah sebagai usaha melawan gaya yang dialami frame-nya, dengan tujuan agar frame tetap di posisinya.

\section{Pusat Massa}

Pusat massa merupakan titik dimana semua massa dari benda tersebut dapat diwakilkan pada satu titik. Pusat massa disebut juga sebagai pusat keseimbangan karena pada titik tersebut massa dari seluruh benda tersebut terwakilkan. Koordinat pusat massa dapat diperoleh dengan persamaan 2 .

$$
\bar{x}=\frac{\sum_{i=1}^{n} m_{i} x_{i}}{\sum_{i=1}^{n} m_{i}}, \quad \bar{y}=\frac{\sum_{i=1}^{n} m_{i} y_{i}}{\sum_{i=1}^{n} m_{i}}
$$

\section{Logika Samar}

Logika samar merupakan teknik kontrol modern yang menggunakan variabel linguistik sebagai parameter pengontrolan. Pengubahan nilai masukan yang berupa nilai tegas ( 0 dan 1 ) dilakukan pada tahap fuzzifikasi [3], yaitu penentuan derajat keanggotaan suatu nilai masukan terhadap drajat keanggotaannya pada kelompok variabel tertentu

Proses selanjutnya adalah proses inference system. Proses ini melakukan pengecekan nilai masukan terhadap aturan-aturan logika samar yang telah dibuat untuk kemudian dilakukan pengambilan keputusan berupa keluaran yang masih dalam bentuk nilai samar $[4,5]$.

Hasil tersebut akan diubah kedalam bentuk nilai tegas dengan melalui proses defuzzifikasi. Dalam pengerjaan penelitian ini metoda defuzzifikasi yang digunakan adalah weight average yaitu dengan merata-ratakan nilai keluaran yang berupa drajat keanggotaan terhadap nilai yang sebenarnya dengan persamaan 3 dengan $\mu_{(y)}$ adalah derajat keanggotaan dari fungsi $Y$ dan $y^{*}$ adalah hasil keluaran yang diharapkan.

$$
y^{*}=\sum \frac{\mu_{(y)} y}{\mu_{(y)}}
$$

\section{3-Phase Brushless DC (BLDC) Motor}

Motor BLDC merupakan synchronous motor, medan magnet yang dihasilkan oleh stator dan rotor berotasi pada frekuensi yang sama. Kecepatan motor BLDC diatur menggunakan sinyal pulse width modulation (PWM) dengan frekuensi $50 \mathrm{~Hz}$. Untuk mencapai kecepatan maksimal, nilai PWM harus dinaikan secara bertahap mulai dari 5\% hingga maksimal 10\% (Gambar 1).

\section{Electronic speed controller (ESC)}

ESC merupakan perangkat elektronik yang digunakan untuk mengatur kecepatan motor.ESC untuk brushless motor bekerja dengan cara menghasilkan tegangan tiga fasa. Tegangan tiga fasa didapat dari tegangan DC yang diolah oleh inverter tiga fasa. Kecepatan motor dapat diatur dengan sinyal PWM dengan rentang 5\%-10\%. Perbandingan lebar pulsa pada sinyal PWM yang diberikan akan mempengaruhi besar frekuensi yang dihasilkan oleh ESC. ESC untuk brushless motor terdiri dari enam buah power transistor yang bekerja sebagai rangkaian switching.

\section{MEMS Motion Sensor LIS302DL}

LIS302DL merupakan sensor accelerometer 3axis yang beroprasi pada tegangan $3.3 \mathrm{~V}$. Sensor ini mampu mendeteksi perubahan percepatan hingga tiga sumbu ortogonal.

Perubahan posisi akibat percepatan yang dirasakan oleh sensor akan diterima dan masuk ke multiplexer untuk proses seleksi data yang masuk secara berurutan. Data berupa tegangan masih sangat kecil, sehingga perlu dikuatkan untuk kemudian diubah menjadi data digital agar memudahkan proses pengolahan data. Data yang sudah dioalah akan dikirim menggunakan komunikasi serial I2C/SPI.

\section{STM32F4 Discovery}

STM32F4 Discovery merupakan development board produksi ST Microelectronics yang menggunakan mikrokontroler berarsiektur ARM seri STM32F407VGT6 dan sudah terintegrasi dengan ST-LINK/V2 sebagai debug tool [6]. Pemrograman mikrokontroler STM32F4 dapat menggunakan software CooCox. Software ini merupakan aplikasi open source yang digunakan untuk memrogram mikrokontroler berarsitektur ARM. Aplikasi ini menyediakan banyak library yang bisa langsung digunakan untuk membuat program. Bahasa pemrograman yang digunakan adalah bahasa $C$ [1].

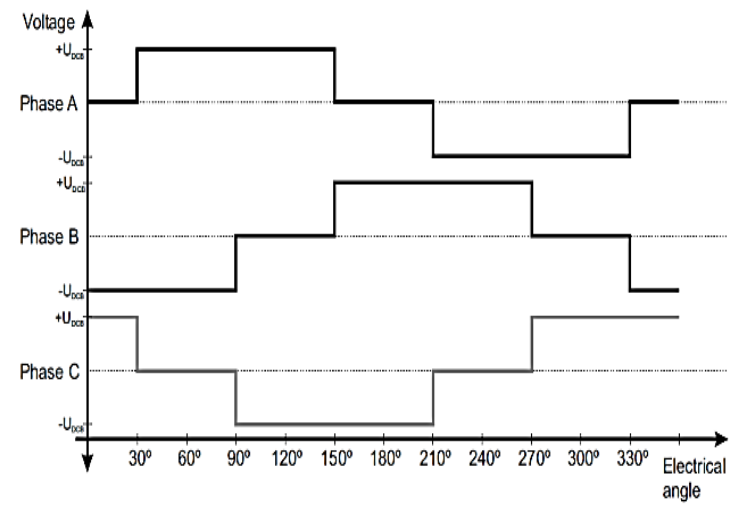

Gambar 1. Bentuk Sinyal untuk Menggerakan 3-Phase BLDC Motor 


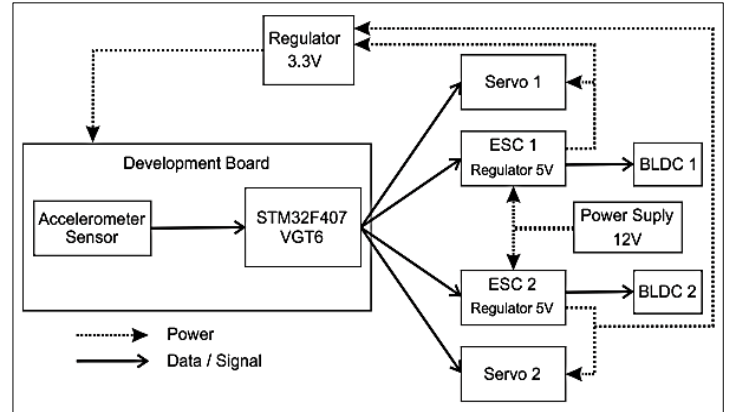

Gambar 2. Diagram Blok Sistem

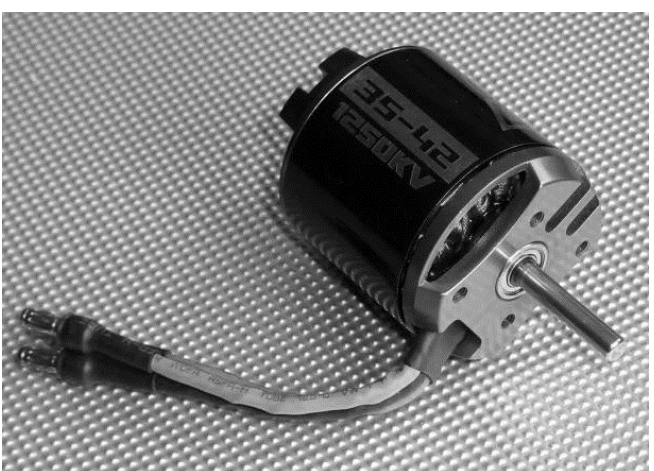

Gambar 3. NTM Prop Drive Series 35-42 A $1250 \mathrm{Kv} 600 \mathrm{~W}$

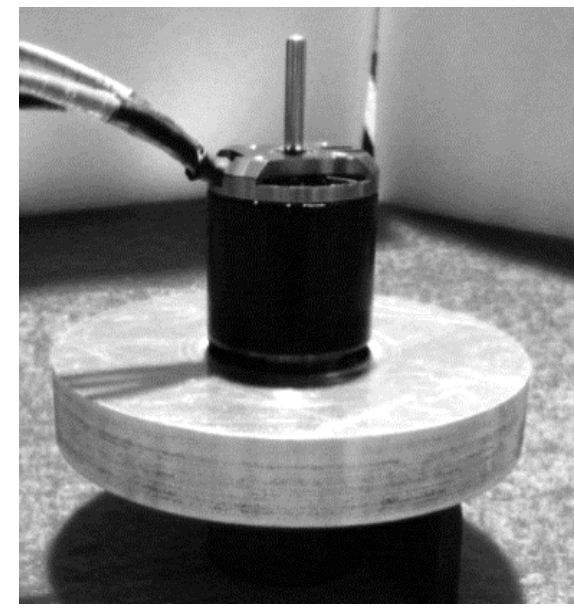

Gambar 4. Rotor Gyroscope

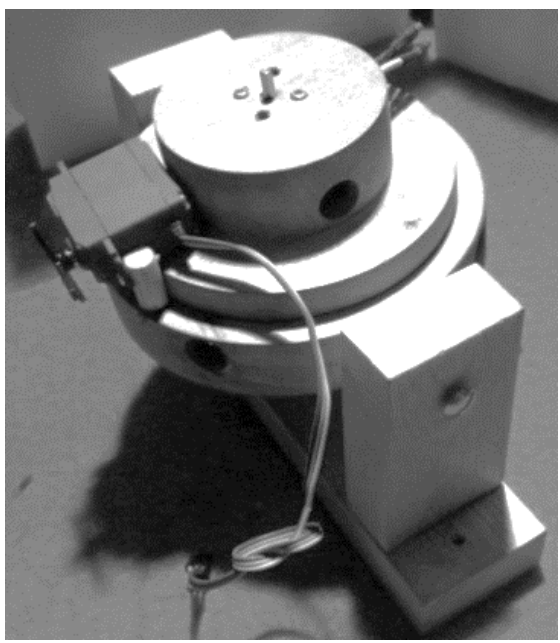

Gambar 5. Gyroscope

\section{Filter Kalman}

Filter Kalman merupakan sebuah filter rekursif [2]. Filter ini mampu memprediksi state pada linear dynamic system dari suatu pengukuran noise. Disebut recursive karena untuk menentukan state estimation saat ini hanya membutuhkan data state estimation sebelumnya dan data pengukuran saat ini. Filter Kalman sangat berguna terutama dalam navigasi dan lingkungan dengan Gaussian noise [7].

Filter Kalman dibagi ke dalam dua bagian utama, yaitu time update dan measurement update. Time update bisa disebut juga sebagai proses predict, yaitu menggunakan estimation state dari waktu sebelumnya untuk mendapatkan sebuah estimation state saat ini. Measurement update bisa disebut juga sebagai proses correct, yaitu menggunakan informasi pengukuran saat ini untuk memperbaiki prediksi dengan tujuan untuk mendapatkan estimation state yang akurat. Filter Kalman akan terus menerus melakukan iterasi predict-correct.

\section{Perancangan Sistem}

Sistem pada penelitian ini terdiri atas sebuah sensor gerak accelerometer LIS302DL yang digunakan sebagai piranti masukan. Sebagai prosesor atau otak yang mengatur sistem, digunakan mikrokontroler ARM Cortex-M4F core berjenis STM32F407VGT6. Pada sisi keluaran sistem, terdiri dari dua buah BLDC dan dua buah motor servo DC analog. Diagram blok perangkat sistem secara keseluruhan ditunjukan pada Gambar 2.

\subsection{Mechanical Gyroscope}

Gyroscope merupakan aktuator utama untuk menjaga keseimbangan kendaraan roda dua. Gyroscope yang digunakan memiliki satu axis karena untuk memberikan respon keseimbangan pada satu sumbu putar. Rotor yang digunakan adalah brushless DC (BLDC) motor. Jenis BLDC motor yang digunakan adalah NTM Prop Drive Series 35-42 A $1250 \mathrm{Kv} 600 \mathrm{~W}$ (Gambar 3).

Bagian kedua dari gyroscope adalah sebuah silinder pejal yang terbuat dari aluminium berdiameter $100 \mathrm{~mm}$ dengan ketebalan $16 \mathrm{~mm}$ dan poros menggunakan besi pejal berdiameter $10 \mathrm{~mm}$ dengan massa total 510 gr. Untuk menjaga kestabilan ketika berputar maka dipasang dua buah bearing yang dipasangkan pada bagian poros. Kedua bearing tersebut diberi dudukan sehingga akan tetap berada diposisinya dan menjaga poros tetap tegak dan lurus.

Kedua buah komponen tersebut merupakan satu kesatuan yaitu sebagai rotor gyroscope (Gambar 4) yang akan selalu berputar dengan kecepatan rata-rata 13500 rpm dengan tujuan dapat menghasilkan momentum sudut yang cukup untuk memberi torsi sebagai usaha melawan gaya akibat gangguan yang diterima. Besar momentum sudut yang dihasilkan oleh gyroscope dapat dilihat pada persamaan 4. 

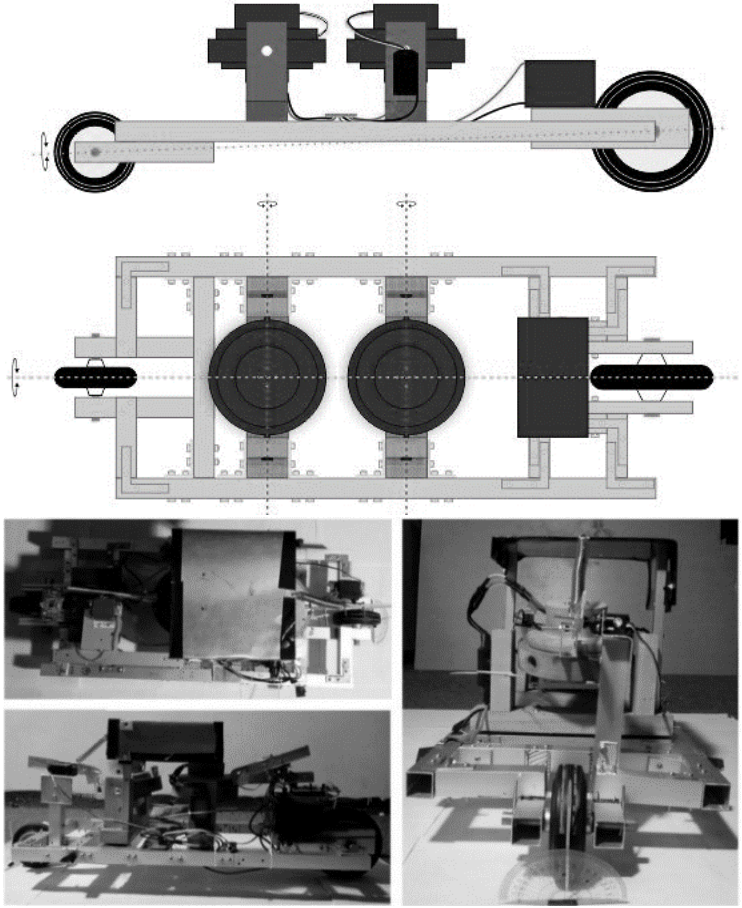

Gambar 6. Konstruksi Kendaraan Roda Dua

$$
\begin{aligned}
L & =I \omega_{s} \\
L & =\frac{1}{2} M R^{2} \omega_{s}=R \frac{1}{2} M R^{2} R P M \frac{2 \pi}{60} \\
L & =\frac{1}{2} 0,51(0,05)^{2} 3500 \frac{2 \pi}{60} \\
L & =0,9 \mathrm{kgm}^{2} \mathrm{~s}^{-1}
\end{aligned}
$$

Gyroscope (Gambar 5) berotasi searah putaran jarum jam untuk menghasilkan arah momentum sudut ke bawah sehingga gaya ke bawah yang bekerja pada sistem semakin besar. Dengan demikian ketika sistem diberi gaya dari samping tidak mudah terganggu.

\subsection{Konstruksi Kendaraan Roda Dua}

Prototipe kendaraan yang telah dirancang menggunakan bahan aluminium sebagai kerangkanya, karena bahan ini ringan dan kuat. Aluminium yang digunakan berbentuk persegi berongga dengan ukuran $25 \times 25 \mathrm{~mm}^{2}$, dan ketebalan $1 \mathrm{~mm}$. Roda belakang terbuat dari karet berdiameter $156,5 \mathrm{~mm}$ dan lebar $30 \mathrm{~mm}$. Roda depan terbuat dari karet berdiameter $100,5 \mathrm{~mm}$ dan lebar $22,3 \mathrm{~mm}$. Panjang total kendaraan adalah $800 \mathrm{~mm}$, lebar 312 $\mathrm{mm}$ dan tinggi $344 \mathrm{~mm}$. Massa total kendaraan roda dua yang dirancang adalah 9,8 Kg. Bentuk konstruksi kendaran roda dua yang dirancang dapat dilihat pada Gambar 6.

\subsection{Sistem Elektronika}

Komponen elektronik utama pada prototipe menggunakan board STM32F4-Discovery produksi ST Microelectronics. Keuntungan menggunakan board ini adalah sebuah mikrokontroler 32-bit ARM Cortex ${ }^{\mathrm{TM}}-\mathrm{M} 4$ yang sudah terintegrasi dengan sebuah motion sensor LIS302DL sebagai sensor kemiringan.

Untuk melakukan pengontrolan dengan metoda logika samar dibutuhkan clock yang cepat karena metoda logika samar menggunakan banyak aturan yang harus selalu diperiksa. Mikrokontroler STM32F407VGT6 yang terdapat pada board mampu melakukan 210 Dhrystone Million Instructions Per Second (DMIPS) yang mampu untuk melakukan pengontrolan dengan metoda logika samar.

Sensor gerak yang sudah terintegrasi akan mempercepat proses pembacaan dan mengurangi kemungkinan data hilang. Sensor gerak yang digunakan mendeteksi perubahan posisi sensor terhadap kemiringan sensor tersebut. LIS302DL mampu mendeteksi gerakan tiga sumbu, yang digunakan dalam penelitian ini hanya satu sumbu karena hanya digunakan untuk mendeteksi kemiringan kendaraan ke kiri atau ke kanan. Tipe data yang dikirimkan oleh sensor berupa sign integer 8-bit (-128 sampai dengan 127), berdasarkan hasil percobaan dengan kondisi tanpa gangguan, ketika sensor dimiringkan maksimum ke kiri menghasilkan data -53 dan maksimum ke kanan menghasilkan data 55. Kekurangan dari sensor ini adalah rentan terkena gangguan ketika diletakkan di bidang yang bergetar. Untuk mengatasi gangguan tersebut, board diletakan di atas baterai karena getaran di atas baterai tidak terlalu besar dan digunakan estimator filter kalman untuk mendapatkan nilai sensor yang valid.

Pengontrolan kecepatan motor dan posisi servo dilakukan dengan menggunakan sinyal PWM berfrekuensi $50 \mathrm{~Hz}$. STM32F407VGT6 memiliki fasilitas TIM yang bisa membangkitkan sinyal PWM dengan frekuensi yang mudah diatur. Dalam pengerjaan penelitian ini menggunakan TIM3 yaitu 16-bit general-purpose timer-counter. TIM3 memiliki empat channel yang bisa diatur secara mandiri. Dua channel untuk mengontrol servo dan dua channel untuk mengatur kecepatan BLDC.

Catu daya yang digunakan adalah sebuah baterai Panasonic 12V/7,2Ah/20HR. Catu daya tersebut digunakan untuk mencatu BLDC, servo, dan board. Catu daya dari baterai masuk ke ESC, di dalam ESC terdapat regulator $5 \mathrm{~V} / 3 \mathrm{~A}$ yang akan digunakan untuk mencatu servo dan board STM32F4-Discovery. Untuk memperkecil arus dan tegangan yang masuk ke board maka level tegangan diubah menjadi 3,3V/1A dengan menggunakan voltage regulator AMS1117 3.3 agar board tidak mengalami over current.

\subsection{Perancangan Perangkat Lunak}

Perancangan perangkat lunak meliputi perancangan sistem kontrol logika samar, filter Kalman untuk memperbaiki nilai masukan dari sensor, dan pengaturan konfigurasi Pulse Width Modulation (PWM). Secara umum proses kerja program yang ditanamkan ke dalam mikrokontroler 
adalah inisialisasi, pengolahan nilai pembacaan sensor, proses logika samar, dan menggerakan servo. Diagram alir proses kerja secara keseluruhan dapat dilihat pada Gambar 7.

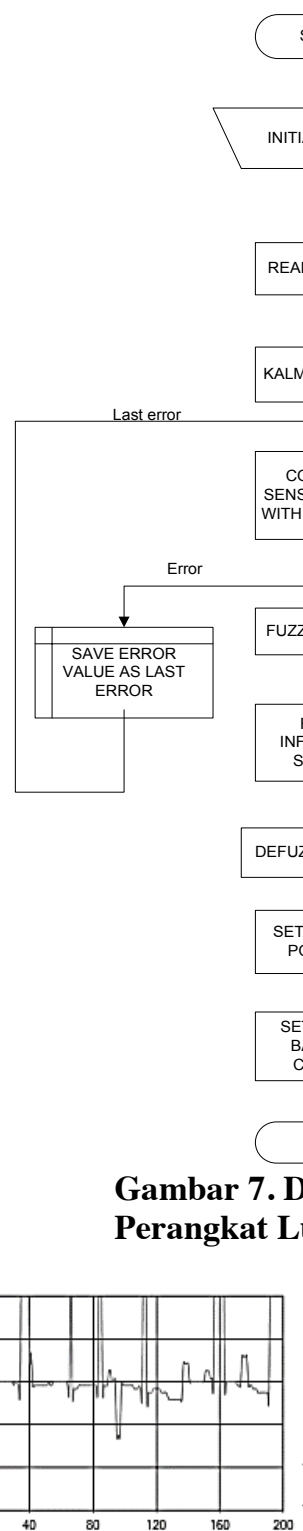

(a)

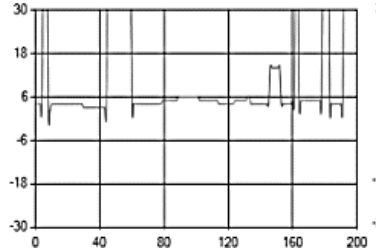

(c)

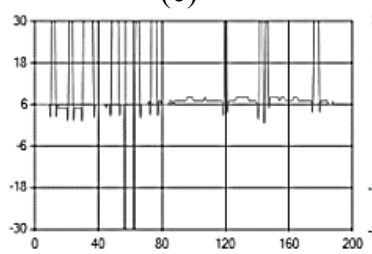

(e)

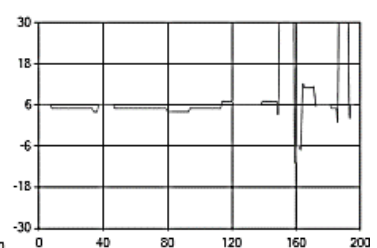

(b)

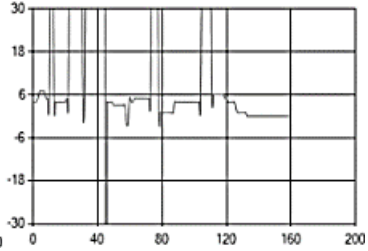

(d)

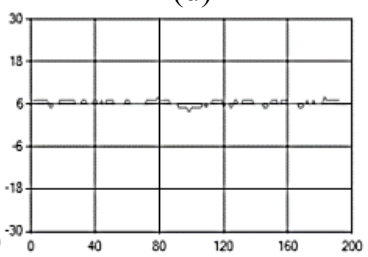

(f)
Gambar 8. Hasil Pengujian
Proses inisialisasi adalah proses persiapan untuk menentukan variabel-variabel yang digunakan selama sistem bekerja. Variabel yang diatur adalah nilai PWM awal untuk masing-masing channel dan mereset nilai variabel error dan delta error. Nilai PWM awal untuk motor BLDC di set dengan duty cycle 5\% sebagai inisialisasi bahwa motor mendapat sinyal untuk berputar. Nilai PWM awal untuk servo depan adalah $8,593 \%$. Nilai PWM awal untuk servo belakang adalah $8,125 \%$. Nilai PWM untuk servo tersebut didapatkan berdasarkan hasil kalibrasi agar posisi gyroscope berada tepat di tengah-tengah rentang pergerakan servo. Setelah semua nilai awal tersebut diatur maka proses selanjutnya adalah menaikan kecepatan motor BLDC hingga nilai PWM mencapai $8,09375 \%$ atau $\pm 13800 \mathrm{rpm}$.

Hasil proses pembacaan nilai sensor diolah hingga bisa dijadikan sebagai masukan proses pengontrolan logika samar. Nilai hasil pembacaan sensor diolah oleh filter Kalman agar noise dapat teredam dan respon pembacaan sensor masih cukup responsif. Nilai hasil filter kalman akan dibandingkan dengan set point. Nilai set point merupakan nilai pembacaan sensor ketika sistem berada pad kondisi tegak. Hasil perbandingan pembacaan sensor dengan nilai set point merupakan nilai error. Nilai error akan disimpan ke dalam variabel last error. Perbandingan nilai error dan nilai last error disebut sebagai delta error. Nilai error dan delta error akan dijadikan sebagai masukan pengontrol logika samar.

Pengolahan Pengontrolan dengan logika samar ada tiga tahap, yaitu mengubah nilai tegas menjadi nilai samar, mengolah nilai samar tersebut berdasarkan aturan yang telah ditentukan, dan kemudian mengembalikan nilai samar menjadi nilai tegas. Proses yang terakhir adalah menggerakkan servo ke posisi yang ditentukan berdasarkan hasil keluaran pengontrol logika samar.

\section{Pengujian dan Analisis}

Hasil pengujian yang pertama ditunjukan pada Gambar 8(a) dilakukan dengan konfigurasi masukan seperti yang ditunjukan pada Gambar 9 dan pengaturan nilai set point adalah 4,5. Untuk memperbesar nilai error maka nilai error dikalikan 1,6. PWM yang diberikan pada kedua motor adalah 1290 dengan tujuan agar kecepatan yang dihasilkan cukup besar dan tidak mengakibatkan gesekan yang terlalu besar sehingga chasing yang terbuat dari kayu tidak cepat terbakar akibat gesekan rotor. Parameter filter Kalman yaitu nilai konstanta measurement variance matrix $(R)$ diset 15 dan process variance matrix $(Q)$ diset 0,3 dengan tujuan agar perbaikan nilai masukan menjadi lebih baik dan respon sistem tidak terlalu lambat.

Pada pengujian pertama, terlihat sistem sudah cukup stabil. Akan tetapi ketika sistem mulai miring, respon servo untuk melawan gaya yang diterima sistem kurang cepat sehingga sistem terjatuh. Noise 
yang diterima oleh sistem masih cukup banyak sehingga diperlukan pengubahan konstanta $R$ dan/atau $Q$ pada filter Kalman untuk memperbaiki nilai masukan logika samar. Respon sistem yang lambat juga disebabkan oleh bentuk fungsi keanggotaan masukan pengontrol logika samar yang kurang sempit sehingga nilai hasil pembacaan masukan error masih dianggap oleh sistem sebagai keadaan yang stabil atau tegak.

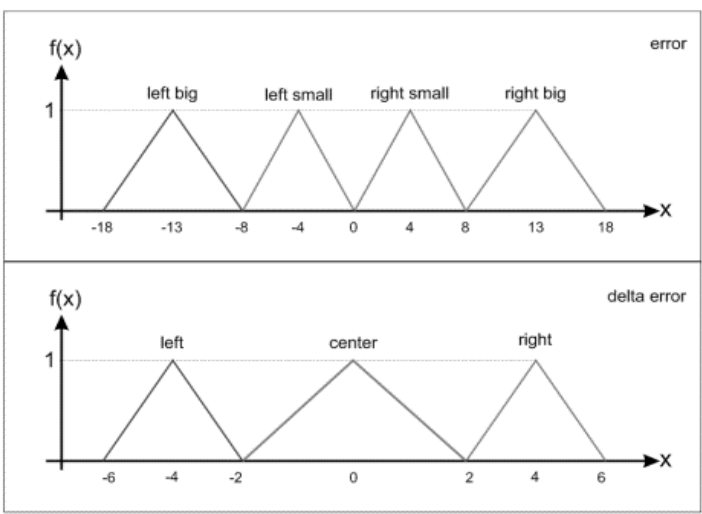

Gambar 9. Fungsi Keanggotaan Masukan Kontrol Logika Samar

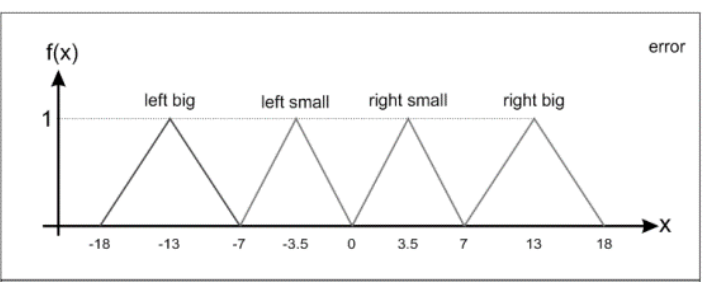

Gambar 10. Fungsi Keanggotaan Masukan Error Dipersempit

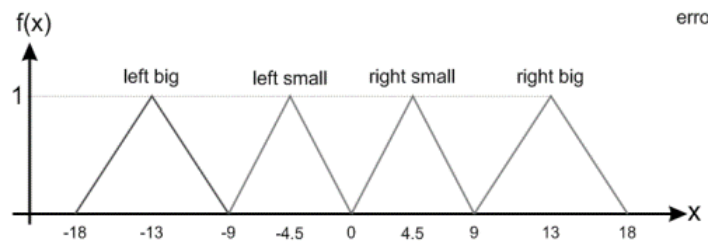

Gambar 11. Fungsi Keanggotaan Masukan Error Diperlebar

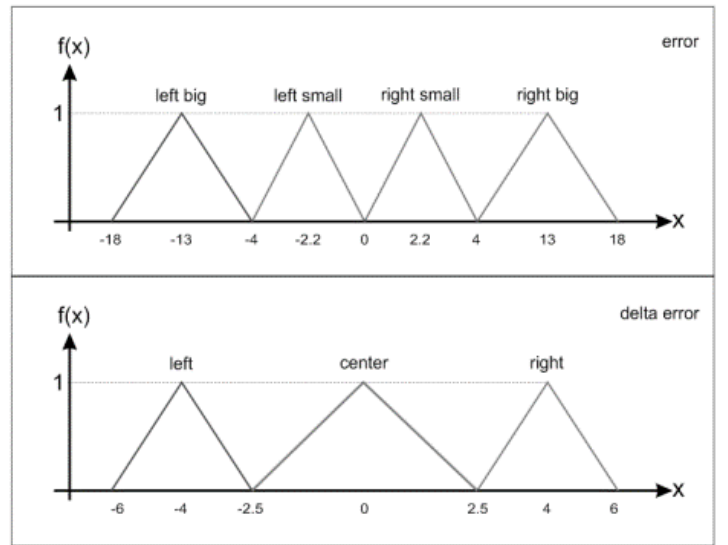

Gambar 12. Fungsi Keanggotaan pada Pengujian Keenam
Pada pengujian kedua, dilakukan pengubahan konstanta $R$ menjadi 20 untuk meredam noise yang diterima oleh sistem. Hasil yang didapatkan adalah noise semakin teredam akan tetapi respon sistem untuk menanggapi perubahan kemiringan menjadi menurun karena perubahan nilai sensor yang diterima sebagai masukan logika samar dianggap kecil sehingga masih dianggap stabil atau tegak.

Pada pengujian ketiga, masih menggunakan konfigurasi pada pengujian pertama, parameter yang diubah adalah konstanta Q menjadi 0,1. Dari hasil pengujian diperoleh bahwa sistem mengalami perbaikan nilai masukan akan tetapi masih terdapat noise yang mengakibatkan sistem merespon secara tiba-tiba sehingga sistem menjadi tidak stabil hingga terjatuh. Respon yang diberikan sistem terhadap perubahan nilai masukan lebih cepat dibandingkan saat pengujian kedua. Meningkatnya respon sistem dibandingkan saat pengujian kedua dikarenakan parameter process variance matrix menjadi lebih kecil sehingga banyaknya variasi untuk diprediksi menjadi lebih sedikit.

Pada pengujian keempat, dilakukan pengaturan konstanta $R=10$ dan $Q=0,1$. Fungsi keanggotaan masukan error diubah menjad seperti ditunjukan pada Gambar 10. Fungsi keanggotaan LEFT SMALL dan RIGHT SMALL dipersempit dengan tujuan membuat sistem semakin responsif.

Hasil yang didapatkan pada pengujian keempat adalah sistem menjadi tidak stabil karena bergesernya hasil perhitungan derajat keanggotaan sehingga keluaran yang dihasilkan bergeser menjadi lebih besar. Ketika keluaran bergeser menjadi lebih besar maka gaya yang dihasilkan menjadi berlebihan sehingga sistem akan memberi gaya balikan yang lebih besar lagi.

Pada pengujian kelima, dilakukan pengaturan konstanta filter Kalman seperti pada pengujian keempat, hanya bentuk fungsi keanggotaan error diperlebar seperti pada Gambar 11. Dari hasil pengujian diperoleh bahwa sistem menjadi lebih stabil ketika sudah berada di posisi tegak akan tetapi banyak noise yang diterima sehingga sistem mudah terganggu kestabilannya. Respon sistem terhadap perubahan kemiringan menjadi lebih lambat karena semakin besar rentang nilai error sehingga sistem akan merespon ketika kemiringan sudah besar sehingga sistem tidak mampu memberikan gaya balik yang cukup untuk kembali tegak.

Pada pengujian keenam dilakukan pengubahan fungsi keanggotaan masukan serta konstanta $R$ menjadi 12 dan $Q$ menjadi 0,2. Bentuk fungsi keanggotaan diatur seperti pada Gambar 12.

Berdasarkan hasil pengujian, sistem sudah cukup stabil, respon sistem cukup cepat, dan sistem mampu mempertahankan posisinya hingga kemiringan $4^{\circ}$ ke kiri dan $5^{\circ}$ ke kanan. Kestabilan sistem tersebut dipengaruhi oleh bentuk fungsi keanggotaan dari kedua masukan, rentang nilai pada fungsi keanggotaan keluaran, serta hasil perbaikan 
nilai masukan oleh filter Kalman. Keterbatasan dari sistem adalah kemampuan sistem memberi gaya balikan untuk kembali ke posisi tegak karena perbandingan torsi yang dihasilkan oleh gyroscope jauh lebih kecil dibandingkan berat total sistem. Keterbatasan tersebut disebabkan oleh konstruksi gyroscope yang perlu peningkatan dari segi ukuran, berat, dan torsi motor servo untuk menggerakan gyroscope.

Pengujian sistem untuk mengetahui ketahanan sistem terhadap gangguan dilakukan dengan menempatkan pemberat pada empat titik yang telah ditentukan seperti ditunjukan pada gambar 13 . Keempat titik tersebut mensimulasikan ketika kendaraan roda dua mengangkut barang di bagian depan dan bagian belakang. Hasil pengujian dapat dilihat pada Tabel 1.

Berdasarkan hasil pengujian seperti ditunjukkan pada Tabel 1, ketika bagian depan sistem diberi gangguan berupa beban, maka sistem lebih mudah terganggu karena pusat massa sistem berada di bagian belakang sehingga pemberian beban di lokasi yang jauh dari pusat massa akan memperbesar torsi akibat gaya yang ditimbulkan oleh benda tersebut dikalikan dengan jaraknya terhadap pusat massa. Ketika sistem diberi gangguan di bagian kiri, sistem mudah terjatuh hal tersebut diakibatkan oleh konstruksi kendaraan roda dua yang lebih condong ke kiri dan akibat pusat massa yang sedikit bergeser ke kanan sehingga torsi yang dihasilkan oleh penambahan beban di sebelah kiri lebih besar.

Ketika sistem diberi gangguan berupa pemberian beban di bagian belakang maka sistem masih bisa menahannya hingga 99 gram. Pemberian gangguan di bagian belakang sistem masih bisa ditahan oleh sistem hingga lebih besar daripada ketika bagian depan sistem yang diberi beban. Hal tersebut dikarenakan tempat peletakan gangguan lebih dekat ke titik pusat massa sehingga torsi yang dihasilkan untuk mengganggu sistem tidak terlalu besar jika dibandingkan dengan ketika bagian depan sistem yang diberi gangguan.

Selama pengujian sistem dengan memberikan gangguan berupa penempatan benda ke titik-titik yang telah ditentukan, sistem mampu mengatasi gangguan tersebut dengan batasan kemiringan sistem $\pm 5^{\circ}$. Ketika kemiringan sistem melebihi $5^{\circ}$, maka sistem tidak mampu untuk kembali ke posisi tegak. Hal ini dipengaruhi oleh bentuk permukaan roda yang bersiku sehingga tidak memungkinkan bagi sistem untuk berada pada kondisi kemiringan diatas $5^{\circ}$.

Secara keseluruhan sistem masih belum berhasil dalam menjalankan fungsinya. Hal tersebut disebabkan oleh keterbatasan konstruksi gyroscope. Torsi yang mampu dihasilkan oleh satu buah gyroscope dengan kecepatan putar $13618 \mathrm{rpm}$ adalah $1,816 \mathrm{Nm}$. Sedangkan berat yang dimiliki oleh sistem sebesar 96,04N. Perlu dilakukan penambahan berat dan dimensi gyroscope untuk mampu menjaga sistem agar tetap tegak.
Tabel 1. Hasil Pengujian Sistem dengan Gangguan Pemberat

\begin{tabular}{|c|c|c|c|c|}
\hline Lokasi & Depan kanan & Depan kiri & Belakang kanan & Belakang kiri \\
\hline Beban & $71 \mathrm{gr}$. & $49 \mathrm{gr}$. & $99 \mathrm{gr}$. & $49 \mathrm{gr}$. \\
\hline
\end{tabular}

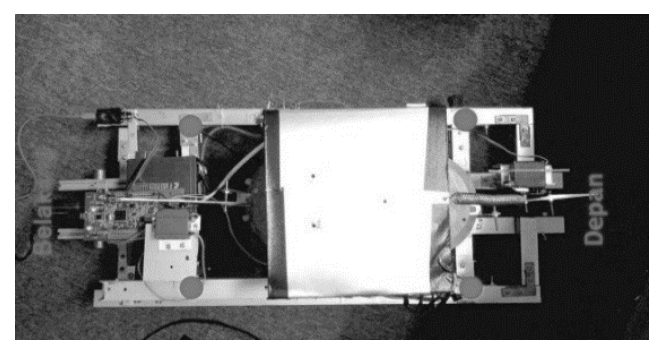

Gambar 13. Lokasi Penempatan Benda Sebagai Gangguan Penguji Kestabilan Sistem

Kondisi gyroscope bagian depan yang tidak sempurna mengakibatkan terjadinya getaran sehingga hasil pembacaan sensor terganggu. Penggunaan filter Kalman masih belum cukup untuk mengatasi geangguan yang ada diperlukan penambahan sensor gyro sebagai pembanding kondisi kemiringan yang dialami oleh sistem. Dengan penambahan sensor gyro maka akan dapat dilakukan metode sensor fusion untuk mendapatkan kondisi kemiringan yang lebih valid.

Pemodelan sistem diperlukan untuk menentukan persamaan pada filter Kalman. Filter Kalman yang digunakan merupakan hasil pemodelan yang belum bisa dipastikan kebenerannya dan kecocokannya terhadap sistem yang telah dirancang sehingga hasilnya belum memuaskan.

\section{Penutup}

\subsection{Kesimpulan}

Dari hasil pengujian dan analisa yang telah dilakukan pada perancangan sistem kontrol keseimbangan kendaraan roda dua dengan metoda logika samar berbasis mikrokontroler dapat diambil beberapa kesimpulan sebagai berikut:

a. Sistem kontrol logika samar yang telah dirancang dan ditanamkan pada prototipe kendaraan roda dua telah sesuai dengan yang diharapkan. Hal ini terlihat dari respon sistem ketika terjadi kemiringan maka sistem memberikan tanggapan berupa gerakan servo yang tidak monoton.

b. Sistem perbaikan nilai masukan dengan menggunakan filter Kalman telah sesuai dengan yang diharapkan. Terlihat dari grafik hasil pengujian bahwa sinyal keluaran filter kalman teredam sesuai dengan besar konstanta $R$ dan $Q$.

c. Gyroscope yang dirancang mampu menjaga keseimbangan sistem dengan batas kemiringan $5^{\circ}$. Gyroscope memiliki torsi sebesar 1,816 Nm ketika berotasi dengan kecepatan $13618 \mathrm{rpm}$.

d. Performansi dari sistem kontrol kendaraan roda dua dengan metoda logika samar dipengaruhi oleh beberapa parameter, yaitu massa total sistem, torsi 
gyroscope, bentuk fungsi keanggotaan logika samar, sensor yang digunakan dan material yang digunakan untuk membangun sistem kendaraan roda dua. Performansi terbaik sistem diperoleh ketika sistem mampu menjaga keseimbangannya ketika diberi gangguan berupa pemberian beban dengan massa 99 gram.

e. Sistem belum berhasil menjalankan fungsinya dengan baik yang diakibatkan oleh ketidak sempurnaan konstruksi gyroscope bagian depan. Getaran yang diakibatkan oleh gyroscope mengakibatkan hasil pembacaan sensor menjadi kacau. Penggunaan filter kalman masih belum cukup untuk mengatasi gangguan yang ada karena pemodelan yang dilakukan belum sesuai dengan sistem yang telah dirancang.

\subsection{Saran}

Pengembangan selanjutnya untuk optimasi keseimbangan dan untuk penyempurnaan sistem secara keseluruhan, dapat dilakukan dengan cara:

a. Menggunakan material kerangka yang mampu meredam getaran sehingga sensor akan lebih optimal dalam mendeteksi terjadinya perubahan kemiringan.

b. Penambahan sensor MEMS gyroscopes sebagai perbandingan nilai getaran yang diterima oleh sensor accelerometer merupakan perubahan kemiringan atau noise. Penggunaan Sensor fusion akan meningkatkan keakuratan pembacaan kemiringan sistem.

c. Rancang gyroscope yang lebih besar dan lebih berat agar momentum sudut yang dihasilkan cukup besar untuk memberi gaya balikan ketika sistem diberi gangguan, serta gunakan servo digital agar memudahkan penentuan posisi kemiringan gyroscope dengan kecepatan yang bisa diatur.

d. Untuk mendapatkan sistem logika samar yang optimal, daoat menggunakan neuro fuzzy logic sehingga lebih optimal ketika menentukan bentuk dan nilai fungsi keanggotaan pada proses fuzzifikasi serta penentuan rule system.

\section{Daftar Pustaka}

[1] Herayanto, Ary, "Pemrograman Bahasa C untuk mikrokontroler ATmega8535", Yogyakarta: Penerbit Andi, 2008.

[2] Kusmanto, Nando, "Rancang Bangun Sistem Navigasi Inersia Dengan Kalman Filter pada Mikrokontroler AVR", Depok: Universitas Indonesia, 2009.

[3] Kusumadewi, Sri dan Sri Hartati, "Neuro Fuzzy", Yogyakarta: Graha Ilmu, 2010.

[4] Kuswadi, Son, "Kendali Cerdas", Yogyakarta: Penerbit Andi, 2007.

[5] Lucian, Teodor, "Fuzzy Controller, Theory, and Applications", India: Intechopen, 2011.
[6] STMicroelectronics, "User Manual STM32F4 Discovery", 2013.

[7] Welch, Greg dan Gary Bishop, “An Introduction to The Kalman Filter", Department of Computer Science, University of North Carolina, diakses tanggal 5 Maret 2013. 